\title{
Social differences associated with the use of psychotropic drugs among men and women aged 65 to 74 years living in the community: the international mobility in aging study (IMIAS)
}

\author{
Gustave Noufou Nana', Boukaré Doulougou ${ }^{1 *}$, Fernando Gomez ${ }^{2}$, Alban Ylli ${ }^{3}$, Jack Guralnik ${ }^{4}$
} and Maria Victoria Zunzunegui ${ }^{1}$

\begin{abstract}
Background: Elderly persons make greater use of psychotropic drugs, but there are few international studies on social differences in the use of these medications. The aim of this study is to examine social differences in the use of psychotropic drugs among persons aged 65-74 years in the International Mobility in Aging Study (IMIAS).

Methods: The sample consisted of 1,995 participants in the IMIAS 2012 baseline study in Saint-Hyacinthe (Canada), Kingston (Canada), Tirana (Albania), Manizales (Colombia), and Natal (Brazil). During home visits, all medication taken by the participants in the previous 15 days was recorded. We then used the Anatomical Therapeutic Chemical classification system to code psychotropic drugs as anxiolytics, sedatives, hypnotics (ASH); antidepressants (ADP); or analgesics, antiepileptics, or antiparkinsonians (AEP). Prevalence ratios for psychotropic drug use according to sex, education, income, and occupation were estimated by fitting a Poisson regression and controlling for demographic and health covariates.

Results: Psychotropic drug use was higher among Canadian participants than among those living outside Canada. Prevalence of AEP drug use was higher for women than men in the Canadian and Latin American sites. In Tirana, antidepressant drugs were rarely used. Socioeconomic differences varied among sites. In the Canadian cities, low socioeconomic standing was associated with higher frequency of psychotropic drug use. In the Latin American cities, elderly people with high education and income levels showed a higher level of antidepressant drug use, while people with manual occupations had a higher use of AEP drugs. In Tirana, ASH drug use was higher among those with low income.
\end{abstract}

Conclusion: An inverse association was observed between socioeconomic standing and psychotropic drug use in Canada, while the opposite was true in Latin America. Albania was notable for an absence of antidepressant use and greater use of ASH drugs among low-income groups.

Keywords: Psychotropic drugs, Aging, Social differences, Latin America, Canada, Albania

\footnotetext{
* Correspondence: boukare.doulougou@umontreal.ca

'Department of Social and Preventive Medicine, School of Public Health, University of Montreal, Montreal, QC, Canada

Full list of author information is available at the end of the article
} 


\section{Background}

Psychotropic drug use is widespread among elderly persons treated at outpatient clinics [1]. These drugs are often prescribed for a variety of reasons, such as insomnia, chronic somatic disease, or symptoms of depression. Inappropriate use has been reported: for example, while antidepressants were being taken by $20 \%$ of participants with depressive symptoms, they were also being taken by $5-12 \%$ of those without depressive symptoms [2]. This could be related to the multiple indications of these drugs, ranging from depression to sleep disorders and neuropathic pain $[3,4]$. Another example is the addiction [5] that can result from prolonged used of anxiolytics [1, 6-8].

Studies have examined factors associated with psychotropic drug use among elderly persons, but the results are sometimes contradictory. In Quebec, the use of anxiolytics, sedatives, and hypnotics, as well as of antidepressants, has been negatively associated with income and education levels of elderly persons $[9,10]$. Studies on elderly persons in the United States and in Northern Europe have found no association between income and education and psychotropic drug use [1113], while in Sweden psychotropic drugs were more often prescribed by psychiatrists to those with the highest levels of education [14]. Among elderly persons in Israel, use of anxiolytics, sedatives, and hypnotics was negatively associated with level of education, while that of antidepressants increased with level of education [1]. In Australia, women, older adults, and persons with lower education were more likely to be antidepressant users [15]. All of these studies were conducted in elderly populations of high-income countries.

The objective of our study was to estimate the association between socioeconomic factors and psychotropic drug use among men and women aged 65-74 years in five different cities in middle- and high-income countries. Our hypothesis was that there are social differences in psychotropic drug use among men and women aged 65-74 residing in these cities and that these differences are research site independent. We expected psychotropic drugs to be more frequently prescribed among populations with lower education, lower income levels, and less skilled employment, as previously reported in most of the studies cited above.

\section{Methods}

Our data come from the International Mobility in Aging Study's (IMIAS) baseline data. IMIAS is a longitudinal, multicentre, and multidisciplinary study focusing on five cities: Kingston (Ontario, Canada), Saint-Hyacinthe (Quebec, Canada), Tirana (Albania), Manizales (Colombia), and Natal (Brazil).
The study population consists of persons between the ages of 65 and 74 years residing and living in the community. The sample was stratified by sex, and the aim was to recruit 200 men and 200 women at each site. The overall sample size across the five research sites was 1,995 persons. The data were collected in 2012.

In Tirana, Manizales, and Natal, participants were recruited from primary healthcare community centres. At these sites, a random sample of elderly persons registered at the health centre was selected, and participants were contacted directly by our investigators with an invitation to participate in the study. All neighbourhood health centres in Manizales, five neighbourhood health centres serving middle- and low-income populations in Natal, and two neighbourhood health centres in Tirana serving middle-class populations participated in the study. In Kingston and Saint-Hyacinthe, potential participants, randomly chosen from the list of patients registered at the participating clinics, received a letter from their family doctor inviting them to contact our field coordinator to set up an appointment for a home visit [16]. In Saint-Hyacinthe, all patients came from the largest family medicine group clinic, with which more than $80 \%$ of physicians are affiliated and which covers the whole territory of the city. In Kingston, the two clinics included in the study are large, covering the whole Central Kingston area. In Saint-Hyacinthe the sample was stratified by neighbourhood, while in Kingston this stratification was not possible. These indirect methods of recruitment in the Canadian cities were required because the ethics committees for the Canadian sites (Queens University and the University of Montreal) did not authorize researchers to communicate directly with potential participants to invite them to participate in a study. The response rate was around $95 \%$ in Tirana, Manizales, and Natal, and around $30 \%$ in Kingston and Saint-Hyacinthe, where $95 \%$ of the potential participants who indicated interest by calling our research coordinator actually participated.

Participants who made four or more errors on the Leganes cognitive test (LCT), a screening test for dementia, were excluded from the interview stage [17]. The data were collected at participants' homes by trained investigators. An interview was conducted, followed by anthropometric and blood pressure measures, as well as tests of mobility and cognitive function, all administered in the appropriate language (English, French, Albanian, Spanish, or Portuguese). The participants were asked whether they had taken any prescribed or over-thecounter medications in the past two weeks. If the answer was positive, the interviewer asked participants to show them all medical drug containers and recorded the drug names. 


\section{Dependent variables}

The data on psychotropic drug use were collected by identifying which of the drugs used by participants during the period covered by the study were psychotropic (analgesic, antiepileptic, antiparkinsonian, anxiolytic, sedative, hypnotic, or antidepressant). Identification was based on the Anatomical Therapeutic Chemical (ATC) classification system recommended by the WHO [18]. For analysis purposes, we grouped psychotropic drug use into four categories corresponding to four dependent variables: 1) AEP - analgesic, antiepileptic, and/or antiparkinsonian drugs (coded N02, N03, or N04); 2) ASH - anxiolytic and/or sedative/hypnotic drugs (coded N05B or N05C); 3) ADP - antidepressant drugs (coded N06A); and 4) MSN, representing use of at least one psychotropic drug (any drug coded N).

\section{Independent variables}

Socioeconomic status was measured using education, income, and occupation indicators.

Education level was self-declared, in answer to the question, "What is the highest level of schooling you have completed?" The answers were grouped into two categories: 'less than secondary school' (for participants who had little education and had not completed secondary school) and 'secondary and above' (for those having completed secondary school or above).

Annual income was determined by asking study subjects, "What is your annual income before taxes?" In Canada, annual income was considered low when it was less than $\$ 20,001$ (Canadian dollars), medium when it was between $\$ 20,001$ and $\$ 40,000$, and high when it was more than $\$ 40,000$. Less than $20,000 \$$ corresponds approximately to "Old Age Security pension" in Canada for a single individual $(17,000 \$)$ or a surviving spouse $(23,000 \$)$ [19]. For Latin America and Albania, low income corresponded to an annual income of $\$ 5,000$ or less, medium income to an annual income from $\$ 5,001$ to $\$ 10,000$, and high income to an annual income greater than $\$ 10,000$. These cut-off points were based on the value of old age pension in Brazil, which is around $\$ 360 /$ month. For analysis, we created two categories: low and medium incomes in one, high income in the other.

Occupation was established by asking the question, "What is the profession or occupation you practiced for the majority of your life?" Occupations were classified according to the International Labour Office's [20] International Standard Classification of Occupations (ISCO08), which distinguishes among 10 occupational groups. For our study, these groups were split into two categories: 'Non-manual occupation' refers to managers and professionals in domains such as science, engineering, health, teaching, or clerical office work; 'manual occupation' refers to manual labourers, agricultural, services, and sales workers, craft and related trade workers, housewives, and other basic occupations.

\section{Potential covariates}

Age, sex, and site of residence were collected. For purposes of comparing frequencies of drug use, the Saint-Hyacinthe and Kingston sites were collectively identified as Canadian sites, while Manizales and Natal were identified as Latin American sites.

Depression and the number of chronic illnesses were taken into account, both to measure health needs and as possible confounding variables. Depression was identified using a screening tool for states of emotional functioning, the Center for Epidemiologic Studies Depression Scale (CES-D) [21]. A score $<16$ indicated the absence of elevated depressive symptomology, while a score $\geq 16$ indicated the presence of elevated symptomology possibly representing depression.

Chronic illnesses taken into account in this study were high blood pressure, diabetes, chronic pulmonary diseases (chronic bronchitis, emphysema, asthma), heart diseases (angina pectoris, heart failure), stroke, and chronic joint damage. For each one, participants were asked whether a health worker had ever told them that they had the illness. Responses were grouped into three categories according to the number of chronic illnesses reported: zero to one, two to three, and four or more.

\section{Statistical analyses}

The proportions of psychotropic drug users were compared using bivariate analyses based on socioeconomic and demographic factors. We conducted sex-specific analyses to document social differences in psychotropic drug use in men and in women separately. The frequencies of users of anxiolytics, sedatives, and hypnotics, of antidepressants, of analgesics/antiepileptics/ antiparkinsonians, and of at least one psychotropic drug were compared through bivariate analysis using chi-square tests. As the use of psychotropic drugs is a generally frequent phenomenon (more frequent than $10 \%)$ and as we were seeking a direct estimation of the prevalence ratio (PR), we adjusted the Poisson regression with a robust variance correction [22]. Given the similarities between the distributions of Kingston and Saint-Hyacinthe on the one hand and those of Natal and Manizales on the other, we pooled the data of the Canadian cities and of the Latin American cities to increase precision of the estimates in multivariate analysis. 
The analyses were conducted using version 19 of the Statistical Package for the Social Sciences (SPSS 19). For all tests, the significance threshold was 0.05 .

\section{Ethical considerations}

The IMIAS study was approved by the research ethics committees of the University of Caldas (Colombia), the Universidade Federal do Rio Grande do Norte (Brazil), the Albanian Institute of Public Health (Albania), Queens University (Canada), and the University of Montreal Hospital Research Centre (Canada). Written informed consent was obtained from all subjects before their participation.

\section{Results}

Our survey involved 1,995 participants after screening for dementia. Ten people were excluded: one each in Kingston, Saint-Hyacinthe, and Tirana, two in Manizales, and five in Natal. All participants who reported taking medication were able to show the corresponding drug containers.

Table 1 shows the distribution of psychotropic drug users and non-users according to selected demographic and socioeconomic characteristics as well as mental and physical morbidity. Women used more psychotropic medication than men in three out of the five cities. Older age was related to increased use in Tirana and Manizales, while low income was related to higher use in the Canadian cities. Depression was related to higher use in Kingston, Manizales, and Natal, and comorbidity was related to higher use at all sites except Tirana $(p=0.72)$ and Kingston $(p=0.22)$.

Table 2 presents psychotropic drug use among men and women by site. In Latin America and Canada, women's frequency of use of AEP and MSN drugs was higher than that of men. Only in Canada did women use ADP drugs more than did men. In Albania, no difference was observed between men's and women's use of psychotropic drugs. At all sites, no difference was observed between men's and women's use of ASH drugs.

At all sites, ASH drug use was not associated with any of the sociodemographic characteristics studied (education, income, occupation) (Table 3). Use of at least one psychotropic drug (MSN) was negatively associated with participant income in Canada. In Latin America only, ADP drug use was negatively associated with education, and participants with non-manual occupations used ADP drugs more than did those in manual occupations. AEP drug use was negatively associated with participant income in Latin America and in Canada. But only in Latin America was the frequency of AEP drug use higher among those with manual professions. In Albania, we did not find any association between use of the various psychotropic drugs and the sociodemographic characteristics studied (Table 3).

Tables 4, 5, and 6 show the prevalence ratios of psychotropic drug use by socioeconomic indicators, after adjusting for age, sex, depression, and number of chronic illnesses. ASH drug use was not significantly associated with education or with occupation at any of the sites. In Albania, however, persons with low to middle incomes had a significantly lower frequency of ASH drug use than those with high income ( $P R=0.43 ; 95 \%$ CI 0.20-0.94) (Table 4).

After adjustment, ADP drug use was negatively associated with education in Latin America $(P R=0.39$; $95 \%$ CI 0.20-0.73), while the reverse was true in Canada ( $\mathrm{PR}=2.55$; $95 \%$ CI 1.23-5.26). Among manual workers in Latin America, ADP drug use was $70 \%$ less than that observed among non-manual workers ( $\mathrm{PR}=0.31 ; 95 \% \mathrm{CI} 0.16-0.59)$. There was no association between income and ADP drug use (Table 5).

After adjustment, there was no significant association between education and AEP drug use at any sites. An association with income was found only in Canada, where persons with low income showed a prevalence of AEP drug use around $60 \%$ higher than that of those with high income (95\% CI 1.06-2.54). And an association with occupation was seen only at the Latin American sites, where persons with manual occupations had a higher frequency of AEP drug use than did those with non-manual occupations ( $\mathrm{PR}=$ 2.63; 95 \% CI 1.07-6.44) (Table 6).

Among users of AEP drugs, $79.4 \%$ of participants (236 out of 301 ) were using only analgesics. A low number of participants had used antiepileptics or antiparkinsonians (35 in Canada, 2 in Albania, and 25 in Latin America).

\section{Discussion}

This study shows that there are socioeconomic differences related to the use of psychotropic drugs among women and men elderly persons living in the community and that these associations go in different directions in Canada and outside of Canada. Our results show that income is the most relevant indicator of socioeconomic differences in the use of psychotropic drugs.

In Canada, a negative association was observed between socioeconomic status and psychotropic drug use. Conversely, in Latin America, persons with high income made greater use of psychotropic drugs. In Albania, antidepressants were not used, but the frequency of use of ASH and AEP drugs was almost as high as in Canada. Also the frequency of use of ASH 
Table 1 Description (in \%) of the study sample by research site (user and non-user refer to any psychotropic drug use)

\begin{tabular}{|c|c|c|c|c|c|c|c|c|c|c|}
\hline & Kingston & & Saint-Hya & the & Tirana & & Manizal & & Natal & \\
\hline & Users & Non-users & Users & Non-users & Users & Non-users & Users & Non-users & Users & Non-users \\
\hline & $(n=108)$ & $(n=290)$ & $(n=123)$ & $(n=278)$ & $(n=118)$ & $(n=276)$ & $(n=97)$ & $(n=303)$ & $(n=38)$ & $(n=364)$ \\
\hline \multicolumn{11}{|l|}{ Sex } \\
\hline Male & 40.7 & 49.0 & 35.0 & 53.2 & 47.5 & 47.8 & 39.2 & 52.8 & 18.4 & 50.8 \\
\hline Female & 59.3 & 51.0 & 65.0 & 46.8 & 52.5 & 52.2 & 60.8 & 47.2 & 81.6 & 49.2 \\
\hline$P$-value & 0.175 & & 0.001 & & 1.000 & & 0.020 & & 0.000 & \\
\hline \multicolumn{11}{|l|}{ Age } \\
\hline $65-69$ & 45.4 & 56.5 & 61.8 & 64.4 & 40.7 & 53.3 & 43.3 & 56.8 & 47.4 & 54.1 \\
\hline 70-74 & 54.6 & 43.5 & 38.2 & 35.6 & 59.3 & 46.7 & 56.7 & 43.2 & 52.6 & 45.9 \\
\hline$P$-value & 0.735 & & 0.653 & & 0.028 & & 0.026 & & 0.495 & \\
\hline \multicolumn{11}{|l|}{ Education } \\
\hline$<$ secondary & 01.85 & 00.00 & 08.94 & 06.12 & 09.32 & 12.32 & 78.35 & 72.28 & 76.32 & 78.02 \\
\hline$\geq$ secondary & 98.15 & 100.00 & 91.06 & 93.88 & 90.68 & 87.68 & 21.65 & 27.72 & 23.68 & 21.98 \\
\hline$P$-value & 0.073 & & 0.297 & & 0.490 & & 0.289 & & 0.838 & \\
\hline \multicolumn{11}{|l|}{ Income } \\
\hline Low/medium & 52.7 & 41.7 & 78.9 & 65.8 & 69.5 & 68.1 & 82.5 & 81.5 & 68.4 & 63.5 \\
\hline high & 47.2 & 57.6 & 17.1 & 30.9 & 30.5 & 31.9 & 17.5 & 18.5 & 31.6 & 36.5 \\
\hline$P$-value & 0.069 & & 0.004 & & 0.814 & & 0.881 & & 0.598 & \\
\hline \multicolumn{11}{|l|}{ Occupation } \\
\hline Non-manual & 75.0 & 76.9 & 45.5 & 50.0 & 39.8 & 34.8 & 11.3 & 16.8 & 15.8 & 09.9 \\
\hline Manual & 25.0 & 23.1 & 54.5 & 50.0 & 60.2 & 65.2 & 88.7 & 83.2 & 84.2 & 90.1 \\
\hline$P$-value & 0.692 & & 0.449 & & 0.361 & & 0.259 & & 0.264 & \\
\hline \multicolumn{11}{|l|}{ Depression } \\
\hline No & 85.2 & 94.1 & 87.8 & 91.4 & 59.3 & 64.1 & 67.0 & 79.9 & 50.0 & 83.5 \\
\hline Yes & 14.8 & 05.9 & 12.2 & 08.6 & 40.7 & 35.9 & 33.0 & 20.1 & 50.0 & 16.5 \\
\hline$P$-value & 0.007 & & 0.276 & & 0.366 & & 0.013 & & 0.000 & \\
\hline \multicolumn{11}{|c|}{ Chronic conditions } \\
\hline Zero or one & 36.1 & 45.9 & 37.4 & 51.8 & 26.3 & 30.1 & 40.2 & 60.4 & 10.5 & 42.3 \\
\hline Two or three & 51.9 & 43.8 & 52.0 & 38.1 & 55.1 & 53.3 & 49.5 & 34.7 & 55.3 & 46.4 \\
\hline Four and more & 12.0 & 10.3 & 10.6 & 10.1 & 18.6 & 16.6 & 10.3 & 04.9 & 34.2 & 11.3 \\
\hline$P$-value & 0.217 & & 0.022 & & 0.722 & & 0.002 & & 0.000 & \\
\hline AEP (yes) & 40.7 & & 54.5 & & 80.5 & & 74.2 & & 60.5 & \\
\hline ASH (yes) & 22.2 & & 34.1 & & 22.0 & & 02.1 & & 26.3 & \\
\hline ADP (yes) & 56.5 & & 34.1 & & 03.4 & & 27.8 & & 28.9 & \\
\hline
\end{tabular}

among Albanian elderly persons was higher for those with high income.

\section{Differences between countries}

The frequency of use of psychotropic drugs was much higher in Canada than in the sites outside Canada. These differences between research sites remained after adjusting for age and sex, depression, and chronic illnesses. The differences in use between countries might be explained by the accessibility of psychotropic drugs in each country's healthcare system and by doctors' training on the therapeutic effects of these drugs for elderly persons. In Canada and Brazil, a medical prescription is required to obtain ASH and ADP medication. In Colombia and Albania, these medical drugs are readily available over the counter without medical prescription. However, the IMIAS database does not have information on the proportion of medication acquired over the counter.

The low frequency of antidepressant use in Albania might be attributable to historical and social phenomena, common to some ex-Soviet countries [23]. First, there is a 
Table 2 Prevalence (\%) of psychotropic drug use by sex for sites in Canada, Latin America, and Albania

\begin{tabular}{|c|c|c|c|c|c|c|c|c|c|c|}
\hline \multirow[t]{2}{*}{ Psychotropic drugs } & \multirow[t]{2}{*}{ Sex } & \multicolumn{3}{|c|}{ Latin America (Natal + Manizales) } & \multicolumn{3}{|c|}{ Canada (Kingston + Saint-Hyacinthe) } & \multicolumn{3}{|c|}{ Albania (Tirana) } \\
\hline & & $N=802$ & (\%) & $P$-value & $N=799$ & $(\%)$ & $P$-value & $N=394$ & (\%) & $P$-value \\
\hline \multirow[t]{2}{*}{ Anxiolytics, sedatives, and hypnotics (ASH) } & Male & 390 & 1.3 & 0.627 & 377 & 6.9 & 0.186 & 188 & 5.3 & 0.328 \\
\hline & Female & 412 & 1.7 & & 422 & 9.5 & & 206 & 7.8 & \\
\hline \multirow[t]{2}{*}{ Antidepressants (ADP) } & Male & 390 & 3.8 & 0.247 & 377 & 9.0 & 0.002 & 188 & 1.6 & 0.272 \\
\hline & Female & 412 & 5.6 & & 422 & 16.4 & & 206 & 0.5 & \\
\hline \multirow{2}{*}{$\begin{array}{l}\text { Analgesics/ antiepileptics/ } \\
\text { antiparkinsonians (AEP) }\end{array}$} & Male & 390 & 7.2 & $<0.001$ & 377 & 10.9 & 0.020 & 188 & 23.9 & 0.938 \\
\hline & Female & 412 & 16.3 & & 422 & 16.6 & & 206 & 24.3 & \\
\hline \multirow[t]{2}{*}{ At least one psychotropic drug (MSN) } & Male & 390 & 11.5 & $<0.001$ & 377 & 23.1 & 0.001 & 188 & 29.1 & 0.947 \\
\hline & Female & 412 & 21.8 & & 422 & 34.1 & & 206 & 30.1 & \\
\hline
\end{tabular}

$P$-value were obtained by Chi-square test

Table 3 Prevalence (\%) of psychotropic drug use according to education, income, and occupation for sites in Canada, Latin America, and Albania

\begin{tabular}{|c|c|c|c|c|c|c|c|c|c|c|c|}
\hline \multirow[t]{2}{*}{ Psychotropic drugs } & \multicolumn{2}{|c|}{$\begin{array}{l}\text { Socioeconomic } \\
\text { variables }\end{array}$} & \multicolumn{3}{|c|}{$\begin{array}{l}\text { Latin America } \\
\text { (Natal + Manizales) }\end{array}$} & \multicolumn{3}{|c|}{$\begin{array}{l}\text { Canada (Kingston + } \\
\text { Saint-Hyacinthe) }\end{array}$} & \multicolumn{3}{|c|}{ Albania (Tirana) } \\
\hline & & & $N=802$ & Percent & $P$-value & $N=799$ & Percent & $P$-value & $N=394$ & Percent & $P$-value \\
\hline \multirow{6}{*}{$\begin{array}{l}\text { Anxiolytics, sedatives, } \\
\text { and hypnotics (ASH) }\end{array}$} & \multirow[t]{2}{*}{ Education } & $<$ Secondary & 608 & 1.8 & \multirow[t]{2}{*}{0.196} & 30 & 10.0 & \multirow[t]{2}{*}{0.724} & 45 & 6.7 & \multirow[t]{2}{*}{0.984} \\
\hline & & $\begin{array}{l}\text { Secondary } \\
\text { or higher }\end{array}$ & 194 & 0.5 & & 769 & 8.2 & & 349 & 6.6 & \\
\hline & \multirow[t]{2}{*}{ Income } & Low/Medium & 584 & 1.0 & \multirow[t]{2}{*}{0.073} & 458 & 9.4 & \multirow[t]{2}{*}{0.141} & 270 & 5.2 & \multirow[t]{2}{*}{0.095} \\
\hline & & High & 218 & 2.8 & & 325 & 6.5 & & 124 & 9.7 & \\
\hline & \multirow[t]{2}{*}{ Occupation } & Manual & 698 & 1.6 & \multirow[t]{2}{*}{0.630} & 300 & 10.3 & \multirow[t]{2}{*}{0.099} & 251 & 6.4 & \multirow[t]{2}{*}{0.812} \\
\hline & & Non-manual & 104 & 1.0 & & 499 & 7.0 & & 143 & 7.0 & \\
\hline \multirow[t]{6}{*}{ Antidepressants (ADP) } & \multirow[t]{2}{*}{ Education } & $<$ Secondary & 608 & 3.8 & \multirow[t]{2}{*}{0.024} & 30 & 23.3 & \multirow[t]{2}{*}{0.082} & 45 & 2.2 & \multirow[t]{2}{*}{0.391} \\
\hline & & $\begin{array}{l}\text { Secondary } \\
\text { or higher }\end{array}$ & 194 & 7.7 & & 769 & 12.5 & & 349 & 0.9 & \\
\hline & \multirow[t]{2}{*}{ Income } & Low/Medium & 584 & 4.6 & \multirow[t]{2}{*}{0.802} & 458 & 14.6 & \multirow[t]{2}{*}{0.147} & 270 & 0.7 & \multirow[t]{2}{*}{0.423} \\
\hline & & High & 218 & 5.0 & & 325 & 11.1 & & 124 & 1.6 & \\
\hline & \multirow[t]{2}{*}{ Occupation } & Manual & 698 & 3.7 & \multirow[t]{2}{*}{$<0.001$} & 300 & 13.3 & \multirow[t]{2}{*}{0.772} & 251 & 1.6 & 0.129 \\
\hline & & Non-manual & 104 & 11.5 & & 499 & 12.6 & & 143 & 0.0 & \\
\hline Analgesics/ antiepileptics/ & Education & $<$ Secondary & 608 & 13.0 & 0.075 & 30 & 23.3 & 0.128 & 45 & 20.0 & 0.493 \\
\hline antiparkinsonians (AEP) & & $\begin{array}{l}\text { Secondary } \\
\text { or higher }\end{array}$ & 194 & 8.2 & & 769 & 13.5 & & 349 & 24.6 & \\
\hline & Income & Low/Medium & 584 & 13.7 & 0.008 & 458 & 17.5 & $<0.001$ & 270 & 25.2 & 0.462 \\
\hline & & High & 218 & 6.9 & & 325 & 8.6 & & 124 & 21.8 & \\
\hline & Occupation & Manual & 698 & 12.9 & 0.017 & 300 & 16.3 & 0.122 & 251 & 22.3 & 0.268 \\
\hline & & Non-manual & 104 & 4.8 & & 499 & 12.4 & & 143 & 27.3 & \\
\hline At least one psychotropic & Education & $<$ Secondary & 608 & 17.3 & 0.558 & 30 & 43.3 & 0.076 & 45 & 24.4 & 0.392 \\
\hline & & $\begin{array}{l}\text { Secondary } \\
\text { or higher }\end{array}$ & 194 & 15.5 & & 769 & 28.3 & & 349 & 30.7 & \\
\hline & Income & Low/Medium & 584 & 18.2 & 0.103 & 458 & 33.6 & $<0.001$ & 270 & 30.4 & 0.788 \\
\hline & & High & 218 & 13.3 & & 325 & 22.2 & & 124 & 29.0 & \\
\hline & Occupation & Manual & 698 & 16.9 & 0.887 & 300 & 31.3 & 0.242 & 251 & 28.3 & 0.340 \\
\hline & & Non-manual & 104 & 16.3 & & 499 & 27.5 & & 143 & 32.9 & \\
\hline
\end{tabular}


Table 4 Prevalence ratios of use of anxiolytics, sedatives, and hypnotics (ASH) according to education, income, and occupation for sites in Canada, Latin America, and Albania

\begin{tabular}{|c|c|c|c|c|c|c|c|c|c|c|}
\hline \multicolumn{2}{|c|}{ Socioeconomic variables } & \multicolumn{3}{|c|}{ Latin America (Natal + Manizales) } & \multicolumn{3}{|c|}{ Canada (Kingston + Saint-Hyacinthe) } & \multicolumn{3}{|c|}{ Albania (Tirana) } \\
\hline & & PR & $95 \% \mathrm{Cl}$ & $P$-value & PR & $95 \% \mathrm{Cl}$ & $P$-value & $P R$ & $95 \% \mathrm{Cl}$ & $P$-value \\
\hline \multirow[t]{4}{*}{ Education } & $<$ Secondary & 3.07 & $0.45-21.20$ & 0.253 & 0.82 & $0.26-2.66$ & 0.747 & 0.84 & $0.25-2.78$ & 0.774 \\
\hline & Secondary or higher & Ref. & & & Ref. & & & Ref. & & \\
\hline & Site 1 & 0.27 & $0.06-1.21$ & 0.087 & 0.58 & $0.36-0.93$ & 0.024 & & & \\
\hline & Site 2 & Ref. & & & Ref. & & & & & \\
\hline \multirow[t]{4}{*}{ Income } & Low/medium & 0.40 & $0.13-1.22$ & 0.109 & 1.14 & $0.67-1.94$ & 0.634 & 0.43 & $0.20-0.94$ & 0.034 \\
\hline & High & Ref. & & & Ref. & & & Ref. & & \\
\hline & Site 1 & 0.33 & $0.07-1.54$ & 0.159 & 0.62 & $0.38-1.01$ & 0.055 & & & \\
\hline & Site 2 & Ref. & & & Ref. & & & & & \\
\hline \multirow[t]{4}{*}{ Occupation } & Manual & 1.44 & $0.18-11.22$ & 0.729 & 1.25 & $0.75-2.07$ & 0.397 & 0.87 & $0.41-1.84$ & 0.709 \\
\hline & Non-manual & Ref. & & & Ref. & & & Ref. & & \\
\hline & Site 1 & 0.27 & $0.06-1.15$ & 0.077 & 0.63 & $0.38-1.04$ & 0.073 & & & \\
\hline & Site 2 & Ref. & & & Ref. & & & & & \\
\hline
\end{tabular}

Controlled for site, age and sex, depression, and number of chronic illnesses, as well as comparison between grouped sites, if applicable

In Latin America, site 1 = Manizales and site 2 = Natal; In Canada, site $1=$ Kingston and site 2 = Saint-Hyacinthe

strong stigmatization of depression, which was generally considered a sign of weakness during Albania's communist period [24]. Thus Albanians, and in particular the elderly, avoided drawing attention to any suffering linked to depression and would resort to denial if questioned. Persons with depression preferred to disclose clinical signs related to difficulties with sleeping. The second phenomenon is linked to health professionals (pharmacists, general practitioners), whose competencies in clinical management of mental diseases are limited due to insufficient training and who often consider depression to be a psychosis [25]. Thus, prescribers consider antidepressants to be a very powerful form of treatment compared to anxiolytics, sedatives, and hypnotics (such as diazepam), which are preferred by these professionals. Finally, antidepressants are prohibitively costly in comparison to ASH or AEP [26, 27].

\section{Differences by sex}

The prevalence of use of all types of psychotropic drugs was higher among women. Considering drug use by site however, the difference between sexes was weak to non-existent at Canadian sites and very significant at research sites outside of Canada. This gender difference has been previously observed in Brazil with benzodiazepines use [28]. As the male-female gap remained after controlling for socioeconomic variables, it is likely related to general differences between men and women at the non-Canadian sites. At these sites, medical prescribers may be more likely to prescribe these

Table 5 Prevalence ratios of antidepressant (ADP) use according to education, income, and occupation for sites in Canada, Latin America, and Albania

\begin{tabular}{|c|c|c|c|c|c|c|c|c|c|c|}
\hline \multicolumn{2}{|c|}{ Socioeconomic variables } & \multicolumn{3}{|c|}{$\begin{array}{l}\text { Latin America (Natal + } \\
\text { Manizales) }\end{array}$} & \multicolumn{3}{|c|}{$\begin{array}{l}\text { Canada (Kingston + Saint- } \\
\text { Hyacinthe) }\end{array}$} & \multicolumn{3}{|c|}{ Albania (Tirana) } \\
\hline & & $\overline{P R}$ & $95 \% \mathrm{Cl}$ & $P$-value & $\overline{P R}$ & $95 \% \mathrm{Cl}$ & $P$-value & $\mathrm{PR}$ & $95 \% \mathrm{Cl}$ & P-value \\
\hline \multirow[t]{3}{*}{ Education } & $<$ Secondary & 0.39 & $0.20-0.73$ & 0.003 & 2.55 & $1.23-5.26$ & 0.011 & - - & -二- & -二- \\
\hline & Secondary or higher & Ref. & & & Ref. & & & & & \\
\hline & Site 1 vs Site 2 & 2.52 & $1.30-4.91$ & 0.006 & 1.61 & $1.09-2.39$ & 0.017 & & & \\
\hline \multirow[t]{3}{*}{ Income } & Low/Medium & 0.53 & $0.26-1.07$ & 0.078 & 1.27 & $0.86-1.89$ & 0.230 & 一一 & -——- & -二— \\
\hline & High & Ref. & & & Ref. & & & & & \\
\hline & Site 1 vs Site 2 & 2.96 & $1.47-5.99$ & 0.002 & 1.52 & $1.04-2.24$ & 0.032 & & & \\
\hline \multirow[t]{3}{*}{ Occupation } & Manual & 0.31 & $0.16-0.59$ & $<0.001$ & 1.31 & $0.88-1.92$ & 0.178 & - - & -——- & - - \\
\hline & Non-manual & Ref. & & & Ref. & & & & & \\
\hline & Site 1 vs Site 2 & 2.47 & $1.26-4.83$ & 0.008 & 1.59 & $1.10-2.31$ & 0.014 & & & \\
\hline
\end{tabular}


Table 6 Prevalence ratios of analgesics/antiepileptics/antiparkinsonians (AEP) use according to education, income, and occupation for sites in Canada, Latin America, and Albania

\begin{tabular}{|c|c|c|c|c|c|c|c|c|c|c|}
\hline \multicolumn{2}{|c|}{ Socioeconomic variables } & \multicolumn{3}{|c|}{ Latin America (Natal + Manizales) } & \multicolumn{3}{|c|}{ Canada (Kingston + Saint-Hyacinthe) } & \multicolumn{3}{|c|}{ Albania (Tirana) } \\
\hline & & $P R$ & $95 \% \mathrm{Cl}$ & $P$-value & $P R$ & $95 \% \mathrm{Cl}$ & $P$-value & $P R$ & $95 \% \mathrm{Cl}$ & $P$-value \\
\hline \multirow[t]{3}{*}{ Education } & $<$ Secondary & 1.36 & $0.81-2.29$ & 0.247 & 1.35 & $0.62-2.94$ & 0.447 & 0.78 & $0.42-1.45$ & 0.440 \\
\hline & Secondary or higher & Ref. & & & Ref. & & & Ref. & & \\
\hline & Site 1 vs Site 2 & 3.53 & $2.28-5.47$ & $<0.001$ & 0.66 & $0.46-0.96$ & 0.028 & & & \\
\hline \multirow[t]{3}{*}{ Income } & Low/Medium & 1.13 & $0.66-1.95$ & 0.651 & 1.64 & $1.06-2.54$ & 0.025 & 1.11 & $0.75-1.66$ & 0.598 \\
\hline & High & Ref. & & & Ref. & & & Ref. & & \\
\hline & Site 1 vs Site 2 & 3.42 & $2.20-5.31$ & $<0.001$ & 0.75 & $0.52-1.08$ & 0.124 & & & \\
\hline \multirow[t]{3}{*}{ Occupation } & Manual & 2.63 & $1.07-6.44$ & 0.034 & 1.16 & $0.81-1.68$ & 0.411 & 0.82 & $0.58-1.17$ & 0.278 \\
\hline & Non-manual & Ref. & & & Ref. & & & Ref. & & \\
\hline & Site 1 vs Site 2 & 3.57 & $2.30-5.54$ & $<0.001$ & 0.68 & $0.47-0.98$ & 0.037 & & & \\
\hline
\end{tabular}

Controlled for site, age and sex, depression, and number of chronic illnesses, as well as comparison between grouped sites, if applicable

In Latin America, site 1 = Manizales and site $2=$ Natal; In Canada, site $1=$ Kingston and site 2 = Saint-Hyacinthe

medications to women [29-35]. Additionally men may be less likely to consult for psychiatric symptoms because they perceived them as a threat to their masculinity [36-38]. This is a topic that would benefit from further international research.

\section{Differences by depressive symptoms and somatic comorbidity}

Finally, as we might have expected, frequency of use of anxiolytics, sedatives, and hypnotics, as well as of antidepressants, was related to higher depressive symptomology. Chronic illness comorbidity, on the other hand, was linked to frequency of use of anxiolytics, sedatives, hypnotics, and analgesics/antiepileptics/antiparkinsonians, but not to that of antidepressants. These results are in agreement with previous reports on anxiolytics (benzodiazepines) use in Brazil [39].

\section{Study strengths and limitations}

Our study has certain limitations, which need to be kept in mind. The first is that the Kingston study sample over-represents highly educated older adults when compared to the reference population of the 2006 Canadian census data. This could have distorted the observed associations. However, the distribution of physical performance in Kingston (gait speed, balance, and time to stand up from a chair) was very similar to that in SaintHyacinthe, the second Canadian city in our study, which was representative in terms of the education, income, and marital status of its reference population. A second limitation is the variation in the meaning of the socioeconomic variable categories. In developed countries such as Canada, manual labour does not have the same implications as it does in middle-income countries. Indeed, the income of elderly persons at the Canadian sites was much higher than that observed at sites in other countries. This is obviously related to the differences in levels of economic development in the countries involved in our study. Standards of education are not the same at the various sites, and education levels of elderly persons are not consistent for the purposes of categorizing the corresponding variable [40, 41]. In our work, each socioeconomic variable was subdivided into two levels to account for the difficulties of comparison linked to the level of economic development of the countries in which study sites were selected. Thus, to help interpret the measures of association, the estimations of associations for the Canadian, Latin American, and Albanian sites were presented by considering the site to be a proxy for the healthcare system, society, and culture of each region. A third limitation concerns the assessment of psychotropic drug use among elderly persons, which was based on use during the two weeks preceding the day of data collection. As such, chronic use and occasional use of psychotropic drugs were considered equivalent, although they are in fact quite different. A fourth limitation is that the IMIAS study did not collect information on elderly persons' beliefs and attitudes with regard to psychotropic drugs, which could be associated with socioeconomic position (in particular education and occupation) and with drug use. Finally, sample size is the fifth limitation. Our results on the association between level of education and the use of ASH, ADP and AEP have to be considered with caution in the case of older Canadian adults, since only 30 people in Canada were in the lowest education category. The lack of significant results for some types of drugs is due to small numbers. As the numbers in some categories of variables did not permit analysis by individual sites, we had to perform analyses by region while controlling for each site.

Despite these limitations, there are clear strengths to our study. First of all, it is the first study of its kind in the countries outside of Canada. We did not find any 
published research on social differences in psychotropic drug use among older adults in these countries. Our study is also one of the first to examine social differences in psychotropic drug use while taking into account these three indicators of socioeconomic position. Another strength was our use of a uniform and rigorous data collection methodology across all five sites. The study was thus able to establish the existence of socioeconomic differences associated with psychotropic drug use between elderly men and women living in different economic contexts.

Finally, given the lack of studies on the use of psychotropic drugs among elderly persons in Brazil, Colombia, and Albania, there is a need for research on the impact of such drug use on the health of the elderly. The role of prescribers in the high use of psychotropic drugs among poorer elderly persons in these countries could be a new avenue for research. An increase in self-medication with analgesic drugs may reflect increasing availability and autonomy of community pharmacists or may indicate abuse of painkillers and anxiolytics to increase general well-being. To generalize our findings and answer these questions, our results would have to be validated through further studies, in different settings.

\section{Conclusion}

There are social differences in the use of psychotropic drugs, but they vary according to societies and healthcare systems. Income appears to be the most relevant factor for predicting social differences related to psychotropic drug use in the elderly population. In Canada, greater antidepressant use was associated with a low level of education and low income, and greater analgesic/antiepileptic/antiparkinsonian drug use was associated with low income. In Latin America, a different pattern emerged. Greater antidepressant use was associated with high education level and strong income, while greater analgesic/antiepileptic/antiparkinsonian drug use was associated with manual occupations. In Albania, antidepressants were not used, and anxiolytics, sedatives, and hypnotics were used more frequently by people with high income.

\section{Competing interests}

The authors declare that they have no competing interests.

\section{Authors' contribution}

GNN designed the study, analysed the data, drafted and reviewed the paper. $\mathrm{BD}$ drafted and reviewed the paper. FG and AY supervised data collection, drafted and reviewed the paper. JG drafted and reviewed the paper. MVZ designed the study, supervised data collection and data analysis, drafted and reviewed the manuscript. All authors read and approved the final manuscript.

\section{Acknowledgements}

We are grateful to all older adults that have given their time and confidence to this research. We would also like to thank our universities and institutes for their continuous support, as well as our funding sources: The Canadian
Institutes of Health (and the Institut de Santé Publique de l'Université de Montréal (IRSPUM)). The authors also thank Mr. Patrick Riley for reviewing the article's language.

\section{Author details}

${ }^{1}$ Department of Social and Preventive Medicine, School of Public Health, University of Montreal, Montreal, QC, Canada. ${ }^{2}$ Research group on gerontology and geriatrics, University of Caldas, Manizales, Colombia. ${ }^{3}$ National Institute of Public Health, Tirana, Albania. ${ }^{4}$ Department of Epidemiology and Public Health, Division of Gerontology, School of Medicine, University of Maryland, Baltimore, MD, USA.

Received: 10 February 2015 Accepted: 6 July 2015

Published online: 20 July 2015

\section{References}

1. Blumstein T, Benyamini Y, Chetrit A, Mizrahi EH, Lerner-Geva L. Prevalence and correlates of psychotropic medication use among older adults in Israel: cross-sectional and longitudinal findings from two cohorts a decade apart. Aging Ment Health. 2012;16(5):636-47.

2. Zhang Y, Chow V, Vitry Al, Ryan P, Roughead EE, Caughey GE, et al. Antidepressant use and depressive symptomatology among older people from the Australian longitudinal Study of Ageing. Int Psychogeriatr. 2010;22(2):437-44.

3. Mojtabai R, Olfson M. Proportion of antidepressants prescribed without a psychiatric diagnosis is growing. Health Aff (Millwood). 2011;30(8):1434-42.

4. Noordam R, Aarts N, Verhamme KM, Sturkenboom MC, Stricker BH, Visser LE. Prescription and indication trends of antidepressant drugs in the Netherlands between 1996 and 2012: a dynamic population-based study. Eur J Clin Pharmacol. 2015;71(3):369-75.

5. Lader M. Long-term anxiolytic therapy: the issue of drug withdrawal. J Clin Psychiatry. 1987;48(Suppl):12-6.

6. Lai HY, Hwang SJ, Chen YC, Chen TJ, Lin MH, Chen LK. Prevalence of the prescribing of potentially inappropriate medications at ambulatory care visits by elderly patients covered by the Taiwanese National Health Insurance program. Clin Ther. 2009;31(8):1859-70.

7. Akazawa M, Imai H, Igarashi A, Tsutani K. Potentially inappropriate medication use in elderly Japanese patients. Am J Geriatr Pharmacother. 2010;8(2):146-60.

8. Ambresin G, Palmer V, Densley K, Dowrick C, Gilchrist G, Gunn JM. What factors influence long-term antidepressant use in primary care? Findings from the Australian diamond cohort study. J Affect Disord. 2015;176:125-32.

9. Allard J, Allaire D, Leclerc G, Langlois SP. The influence of family and social relationships on the consumption of psychotropic drugs by the elderly. Arch Gerontol Geriatr. 1995;20(2):193-204.

10. Bossé C. Caracterisation de la consommation d'antidepresseurs chez les personnes âgées vivant à domicile. In: Université de Sherbrook. Sherbrook: Université de Sherbrook; 2012.

11. Dealberto MJ, Seeman T, McAvay GJ, Berkman L. Factors related to current and subsequent psychotropic drug use in an elderly cohort. J Clin Epidemiol. 1997;50(3):357-64.

12. Rubio-Valera M, Fernandez A, Luciano JV, Hughes CM, Pinto-Meza A, Moreno-Kustner B, et al. Psychotropic prescribing in Catalonia: results from an epidemiological study. Fam Pract. 2012;29(2):154-62.

13. Gustafsson T, Isacson D, Thorslund M, Sorbom D. Factors associated with psychotropic drug use among the elderly living at home. J Applied Gerontol. 1996;15(2):238-54.

14. Wastesson JW, Fastbom J, Ringback Weitoft G, Fors S, Johnell K. Socioeconomic inequalities in access to specialized psychotropic prescribing among older Swedes: a register-based study. Eur J Public Health. 2014;24(6):991-6.

15. Paige E, Korda RJ, Kemp A, Rodgers B, Banks E. Characteristics of antidepressant medication users in a cohort of mid-age and older Australians. Aust N Z J Psychiatry. 2015;49(3):275-90.

16. Sousa AC, Guerra RO, Thanh Tu M, Phillips SP, Guralnik JM, Zunzunegui MV. Lifecourse adversity and physical performance across countries among men and women aged 65-74. PLoS One. 2014;9(8), e102299.

17. De Yebenes JG, Sanchez M, Mena MA. Neurotrophic factors for the investigation and treatment of movement disorders. Neurotox Res. 2003;5(1-2):119-38. 
18. WHO Collaborating Centre for Drug Statistics Methodology. Anatomic Therapeutic Chemical / Defined Daily Dose Index 2015. Oslo: 2015. Available at: http://www.whocc.no/atc_ddd_index/. Accessed 15 January, 2015.

19. Government of Canada. People serving people: Old age security payment amounts. Ottawa: Government of Canada; 2015. Available at: http:// www.servicecanada.gc.ca/eng/services/pensions/oas/payments/ index.shtml?utm_source=vanity+URL\&utm_medium=print +publication, +ISPB-185,+ISPB-341\&utm term =/ oasamounts\&utm_content=Mar+2013,+eng\&utm_campaign=OAS+Pension +2013,+Benefits+for+Low+Income+Seniors Accessed June 02, 2015.

20. ILO. International Standard Classification of Occupations (ISCO-08). International Labour Office, Geneva 2012; 1:http://www.ilo.org/public/ english/bureau/stat/isco/isco08/.

21. Radloff LS. The CES-D scale: A self-report depression scale for research in the general population. Appl Psychol Meas. 1977;1:385-401.

22. Barros AJ, Hirakata VN. Alternatives for logistic regression in cross-sectional studies: an empirical comparison of models that directly estimate the prevalence ratio. BMC Med Res Methodol. 2003;3:21.

23. Petrea I, Haggenburg M. Chapter 10: Mental health care. In: Rechel B, Richardson E, McKee M, editors. Trends in health systems in the former Soviet countries. Copenhagen: WHO; 2014. p. 159-72.

24. Petrea I. Mental health in former Soviet countries: From past legacies to modern practices. Public Health Rev. 2013;34:2.

25. World Health Organization. Mental health atlas-2011 country profiles : Albania. WHO: WHO; 2011. Available at: http://www.who.int/mental_health/ evidence/atlas/profiles/alb_mh_profile.pdf?ua=1. Accessed June 9, 2015

26. Kakariqi L. Konsumi i barnave te rimbursueshem ne Shqiperi. Tirana: Marin Barleti; 2014

27. Richardson E, Sautenkova N, Bolokhovets G. Chapter 9: Pharmaceutical care. In: Rechel B, Richardson E, McKee M, editors. Trends in health systems in the former Soviet countries. Copenhagen: WHO; 2014. p. 145-58.

28. Alvarenga JM, Loyola Filho Al, Firmo JO, Lima-Costa MF, Uchoa E. Prevalence and sociodemographic characteristics associated with benzodiazepines use among community dwelling older adults: the Bambui Health and Aging Study (BHAS). Rev Bras Psiquiatr. 2008;30(1):7-11.

29. Bierman AS, Pugh MJ, Dhalla I, Amuan M, Fincke BG, Rosen A, et al. Sex differences in inappropriate prescribing among elderly veterans. Am J Geriatr Pharmacother. 2007:5(2):147-61.

30. Huang B, Bachmann KA, He X, Chen R, McAllister JS, Wang T. Inappropriate prescriptions for the aging population of the United States: an analysis of the national ambulatory medical care survey, 1997. Pharmacoepidemiol Drug Saf. 2002;11(2):127-34

31. Blumstein T, Benyamini Y, Shmotkin D, Lerner-Geva L. Gender differences in the prevalence and correlates of psychotropic medication use among older adults in Israel. Isr J Psychiatry Relat Sci. 2014;51(2):118-25.

32. Hohmann AA. Gender bias in psychotropic drug prescribing in primary care. Med Care. 1989;27(5):478-90.

33. Lane CJ, Bronskill SE, Sykora K, Dhalla IA, Anderson GM, Mamdani MM, et al. Potentially inappropriate prescribing in Ontario community-dwelling older adults and nursing home residents. J Am Geriatr Soc. 2004;52(6):861-6.

34. Swami V. Mental health literacy of depression: gender differences and attitudinal antecedents in a representative British sample. PLoS One. 2012;7(11), e49779.

35. van der Waals FW, Mohrs J, Foets M. Sex differences among recipients of benzodiazepines in Dutch general practice. BMJ. 1993:307(6900):363-6.

36. Addis ME, Mahalik JR. Men, masculinity, and the contexts of help seeking. Am Psychol. 2003;58(1):5-14.

37. Galdas PM, Cheater F, Marshall P. Men and health help-seeking behaviour: literature review. J Adv Nurs. 2005;49(6):616-23

38. McVittie C, Willock J. "You can't fight windmills": how older men do health, ill health, and masculinities. Qual. Health Res. 2006;16(6):788-801.

39. Alvarenga JM, Loyola Filho Al, Firmo JO, Lima-Costa MF, Uchoa E. A population based study on health conditions associated with the use of benzodiazepines among older adults (The Bambui Health and Aging Study). Cad Saude Publica. 2009;25(3):605-12.

40. Lynch JW, Kaplan GA. Socioeconomic factors. In: Berkman LF, Kavachi I, editors. Social Epidemiology. New York: Oxford University Press; 2000. p. 13-35.

41. Grundy E, Holt G. The socioeconomic status of older adults: how should we measure it in studies of health inequalities? J Epidemiol Community Health. 2001;55(12):895-904.

\section{Submit your next manuscript to BioMed Central and take full advantage of:}

- Convenient online submission

- Thorough peer review

- No space constraints or color figure charges

- Immediate publication on acceptance

- Inclusion in PubMed, CAS, Scopus and Google Scholar

- Research which is freely available for redistribution

Submit your manuscript at www.biomedcentral.com/submit

C Biomed Central 